\title{
Interactions of Galanin with Endomorphin-2, Vasopressin and Oxytocin in Nociceptive Modulation of the Trigemino-Hypoglossal Reflex in Rats
}

\author{
M. ZUBRZYCKA ${ }^{1}$, A. JANECKA ${ }^{2}$ \\ ${ }^{1}$ Department of Experimental Physiology and ${ }^{2}$ Laboratory of Biomolecular Chemistry, Medical \\ University, Lodz, Poland
}

Received May 17, 2007

Accepted July 11, 2007

On-line October 11, 2007

\begin{abstract}
Summary
Galanin (GAL) is suggested to be a neuropeptide involved in pain transmission. In this study we tried to determine, whether the increase of GAL concentration in brain cells affects impulse transmission between the motor centers localized in the vicinity of the third and fourth cerebral ventricles. The experiments were carried out on rats under chloralose anesthesia. The study objectives were realized using the method allowing to record the amplitude of evoked tongue jerks (ETJ) in response to noxious tooth pulp stimulation during the perfusion of the cerebral ventricles with solutions containing tested compounds. Perfusion of the cerebral ventricles with GAL concentration-dependently inhibited the ETJ amplitude. The antinociceptive effect of GAL was blocked by a galanin receptor antagonist, galantide (GLT) and by opioid antagonists: non-selective naloxone ( $\mathrm{Nal}$ ) and $\mu$ selective $\beta$-funaltrexamine ( $\beta$-FNA). In contrast, a $\delta$-opioid receptor antagonist, naltrindole (NTI) or the $\mathrm{k}$-opioid receptor antagonist, nor-binaltrophimine (nor-BNI) did not inhibit the effect of GAL. The antinociceptive effect of GAL was more pronounced when GAL was perfused in combination with other neuropeptides/neurohormones, such as endomorphin-2 (EM-2), vasopressin (AVP) and oxytocin (OT). The present results demonstrate that in the orofacial area analgesic activity is modulated by GAL, OT and AVP and that EM-2-induced antinociception involves GAL.
\end{abstract}

\section{Key words}

Antinociception • Galanin • Vasopressin • Oxytocin • Galanin antagonist $\bullet$ Opioid antagonists $\bullet$ Perfusion of cerebral ventricles

\section{Corresponding author}

Maria Zubrzycka, Department of Experimental and Clinical Physiology, Medical University of Lodz, 90-215 Lodz, ul. Mazowiecka 6/8, Poland. Fax: (4842) 6784277. E-mail: ajanecka@zdn.am.lodz.pl

\section{Introduction}

Galanin (GAL) is a 29/30-amino-acid neuropeptide (Tatemoto et al. 1983) present in the central nervous system (CNS) together with other neuromediators. GAL exerts its biological effect by interacting with three high affinity cell surface receptors GALR1-3, which all belong to the family of G-protein coupled receptors (Branchek et al. 1998, 2000, Iismaa and Shine 1999, Waters and Krause 2000) GAL has been shown to be involved in a variety of physiological processes (Gundlach 2002, Rajendren 2002, Wiesenfeld-Hallin and Xu 2001). A substantial body of work suggests that GAL plays an important role as a modulator in pain perception (JimenezAndrade et al. 2005, Liu and Hökfelt 2002, Malkmus et al. 2005, Sun and Yu 2005, Wiesenfeld-Hallin and Xu 2001, $\mathrm{Xu}$ et al. 2000a). It has been proposed that GAL produces a biphasic, dose-dependent effect on nociception through activation of antinociceptive (inhibitory) GALR1 or pronociceptive (excitatory) GALR2 receptors (Liu and Hökfelt 2002, Xu et al. 2000b). The complex effect of GAL on nociception is assumed to be a result of differential activation of the GAL receptor subtypes (Liu and Hökfelt 2002, Xu et al. 2000b). There are also multiple lines of evidence suggesting that under normal conditions, the effect of exogenous GAL is predominantly inhibitory (Hua et al. 2004, Xu et al. 2000b) due to blocking the excitatory effect of substance $\mathrm{P}$ and calcitonin gene-related peptide (Hua et al. 2005, Xu et al. 1990).

In many rat and human CNS structures, GAL is co-expressed with other neurohormones or neuromediators. Most neurons of the hypothalamic 
paraventricular nuclei (PVN) and supraoptic nuclei (SON) contain GAL, co-localized with vasopressin (AVP) (Gai et al. 1990, Jimenez-Andrade 2005, 2003, Landry and Hökfelt, 1998, Melnikowa et al. 2006), oxytocin (OT) (Gai et al. 1990, Melnikowa et al. 2006) and opioids (Sanchez et al. 2001). The hypothalamus is known to be one of the key structures involved in pain modulation and transmission (Dafny et al. 1996). The hypothalamic fibers containing opioid neurons, terminate in periaqueductal central gray (PAG) (Pilcher et al. 1988), which plays an important role in ascending antinociceptive pathways (Sandküchler 1996, Wang et al. 1999, 2000). Descending vasopressinergic and oxytocinergic pathways extend from the hypothalamus to the brain stem. Hypothalamic fibers containing AVP and OT, modulating afferent noxious stimuli, project to the thalamus, medulla oblongata (including the trigeminal nerve nuclei) and the substantia gelatinosa of the dorsal horn of the spinal cord (Sawchenko and Swanson 1982).

The antinociceptive role of GAL at the spinal level has been extensively studied (Blakeman et al. 2003, Hua et al. 2005, Liu et al. 2001, Liu and Hökfelt 2002, Wiesenfeld-Hallin et al. 2005), whereas the role of GAL in nociceptive transmission in the orofacial area remains to be elucidated. The co-existence of GAL with AVP, OT and opioids in the hypothalamus prompted us to study the interactions between these neuropeptides/neurohormones in pain processing, i.e. in the trigemino-hypoglossal reflex induced by tooth pulp stimulation in rats.

\section{Methods}

\section{Experimental animals and anesthesia}

The experimental protocol in the present study was approved by the Local Ethical Committee for Animal Research and it complies with the European Community guidelines for the use of experimental animals. Male Long-Evans rats weighing 330-360 g were used for the experiments. The animals were kept under standard conditions: temperature $22{ }^{\circ} \mathrm{C}$, a $12 \mathrm{~h}$ light-dark cycle, and allowed tap water and rodent chow ad libitum. The rats were anesthetized with a single intraperitoneal injection of chloralose solution in a dose of $150 \mathrm{mg} / \mathrm{kg}$ body weight. Chloralose does not eliminate completely transmission in the ascending reticular formation, which constitutes a non-specific pathway for sensory impulsation and therefore does not interfere with synaptic transmission between sensory neurons and allows recording ETJ amplitude. For each experiment ten animals were used.

\section{Chemicals}

The artificial cerebrospinal fluid (aCSF) was prepared according to Daniel and Lederis (1967) and contained: $120 \mathrm{mM} \mathrm{NaCl}, 4.8 \mathrm{mM} \mathrm{KCl}, 2.8 \mathrm{mM} \mathrm{CaCl}_{2}$, $1.2 \mathrm{mM} \mathrm{KH}_{2} \mathrm{PO}_{4}, 1.3 \mathrm{mM} \mathrm{MgSO}, 26 \mathrm{mM} \mathrm{NaHCO}$, $10 \mathrm{mM}$ glucose, $1.0 \mathrm{~g} / \mathrm{l}$ bovine serum albumin and $0.1 \mathrm{~g} / 1$ ascorbic acid $(\mathrm{pH}=7.4-7.5)$. The solution was placed in a water bath at $37{ }^{\circ} \mathrm{C}$ and constantly gassed with carbogen (a mixture of $95 \% \mathrm{O}_{2}$, and $5 \% \mathrm{CO}_{2}$ ). Solutions for intracerebroventricular (i.c.v.) perfusions were prepared in aCSF: 100 and $200 \mathrm{nM}$ galanin (GAL) (Tocris, Bristol, UK), $100 \mathrm{nM}$ galantide (GLT) (Bachem, Switzerland), $100 \mathrm{nM}$ naloxone hydrochloride (Nal) (Sigma, St. Louis, MO, USA), $100 \mathrm{nM} \beta$-funaltrexamine hydrochloride ( $\beta$ FNA) (Tocris, Bristol, UK), $100 \mathrm{nM}$ nor-binaltorphimine dihydrochloride (nor-BNI) (Tocris, Bristol, UK), $100 \mathrm{nM}$ naltrindole (NTI) (Tocris, Bristol, UK); $100 \mathrm{nM}$ oxytocin (OT) and vasopressin (AVP) (Peninsula Laboratories Inc., San Carlos, CA, USA) and $100 \mathrm{nM}$ endomorphin-2 (EM-2), which was synthesized in our laboratory, as described elsewhere (Janecka et al. 2004).

\section{Perfusion of cerebral ventricles in rats}

The rat's head was immobilized by introduction of ear bars into the external auditory meati and fixing the maxilla with jaw clamps in a stereotaxic instrument specially adapted for perfusion of the cerebral ventricles (Zubrzycka et al. 1997). The skin of the animal's head, anesthetized with $2 \%$ polocaine solution, was incised in the midline and the skull bones were exposed. On the basis of co-ordinates given by De Groot's stereotaxic atlas (1963), the sites for drilling holes in the skull bones were determined: to the lateral ventricles - $9 \mathrm{~mm}$ anterior to the frontal interaural zero plane and $3 \mathrm{~mm}$ lateral to the sagittal zero plane. The system of cerebral ventricles was perfused by inserting stainless steel cannulae into both lateral ventricles and to the cerebellomedullary cistern. The container with perfusion fluid was positioned $20 \mathrm{~cm}$ above the animal's head. The outflow cannula, inserted into the cerebellomedullary cistern, was connected to a polyethylene tube ca $100 \mathrm{~cm}$ long which provided the outflow for the perfusion fluid. The flow rate at the end of the tubing during perfusion was $0.5-0.7 \mathrm{ml} / 10 \mathrm{~min}$. After control perfusion with aCSF the cerebral ventricles were perfused with peptide solutions. There were 5-min intervals between solutions. 
A B
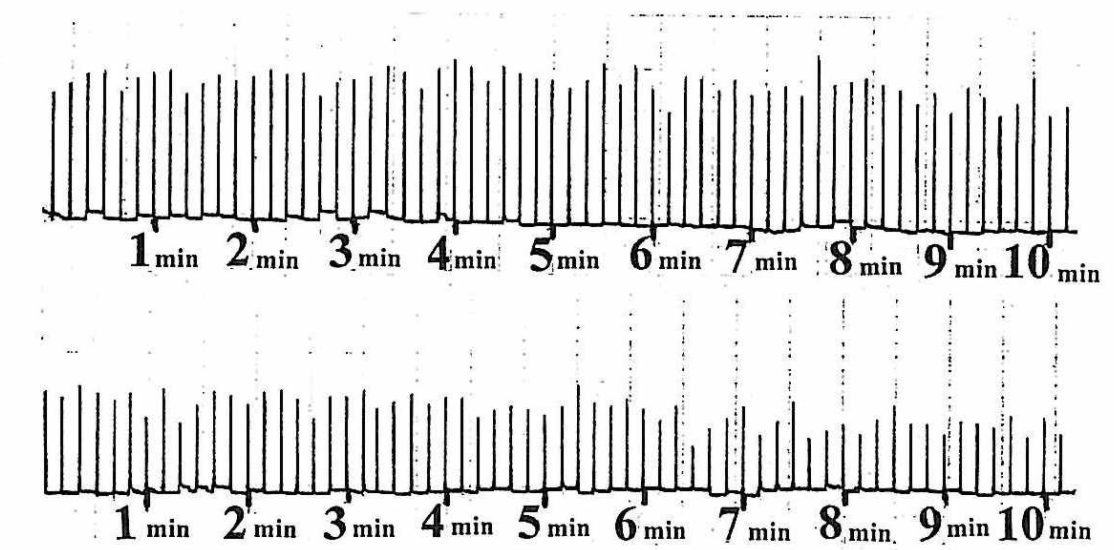

Fig. 1. Original recordings of evoked tongue jerks (ETJ) induced by incisor pulp stimulation in rat during perfusion of cerebral ventricles: 10 min control perfusion with aCSF, mean amplitude $22 \mathrm{~mm}$ (A) and $10 \mathrm{~min}$ perfusion with $200 \mathrm{nM} \mathrm{GAL}$, mean amplitude 11 $\mathrm{mm}(\mathrm{B})$.

\section{Tooth pulp stimulation}

After placing the animal's head in a stereotaxic instrument, the tips of both lower incisors were cut off with a dental separator and stainless steel wire electrodes were inserted into the pulp and fixed with dental cement (Duracil, Spofa). The pulp bipolar stimulation was delivered 6 times per minute, with a train of four electrical impulses, of $200 \mathrm{~Hz}$ frequency, $3 \mathrm{~ms}$ single impulse duration with $2 \mathrm{~ms}$ intervals and 4-6 V amplitude, using a programmed stimulator. Trains of 4 impulses were delivered to the pulp at $10 \mathrm{~s}$ intervals. A Grass stimulator, model S4K, connected with a gating circuit, was used. The amplitudes of electrical impulses stimulating the incisor pulp were adjusted individually for each animal. At the beginning of each experiment the intensity of stimulus inducing maximum tongue jerks was determined. Then, the amplitude of impulses was reduced to obtain the amplitude of tongue jerks equal to half of the maximum values. The amplitude of stimulating impulses adjusted in this way, as well as their other parameters, remained unchanged till the end of the experiment.

\section{Recording tongue jerks}

The tip of the animal's tongue was attached with a silk thread to an isotonic rotating tensometric transducer. The amplitude of tongue jerks was recorded on a paper using a Line Recorder TZ-4620 (Laboratorní prŕstroje, Prague, Czech Republic). For each animal during the first $10 \mathrm{~min}$ of perfusion or with $10 \mathrm{~min}$ after injection the amplitude of tongue jerks evoked by tooth pulp stimulation was recorded. The mean amplitude of tongue jerks by tooth pulp stimulation was regarded as an indicator of magnitude of the trigemino-hypoglossal reflex. Mean amplitudes of ETJ induced by tooth pulp stimulation during perfusion the control solution (aCSF) and with peptide solutions, were compared separately.

\section{Statistical analysis}

Statistical analyses were performed using Prism 4.0 (GraphPad Software Inc.). The data are expressed as means \pm SEM. Differences between groups were assessed by one-way analysis of variance (ANOVA) followed by a post-hoc multiple comparison Student Newman-Keuls test. Antagonist effects in the combination experiments were analyzed using two-way analysis of variance (ANOVA) and a post-hoc multiple comparison Student Newman-Keuls test was used for multiple comparisons between groups. A probability level of $p<0.05$ or lower was considered as statistically significant.

\section{Results}

Antinociceptive activity of galanin in the trigeminohypoglossal reflex in rats

Cerebral ventricles were perfused with GAL in 50, 100 and $200 \mathrm{nM}$ concentration. To obtain an effect of a peptide perfused i.c.v. it is necessary to get an appropriate concentration of this peptide in the extracellular fluid in the sensory and motor centers for trigemino-hypoglossal reflex. These centers are located in the vicinity of the fourth cerebral ventricle wall, so the perfused peptide is first diluted in the CSF and then it diffuses through the whole cerebroventricular and cerebromedullary cistern wall area to the extracellular fluid of the brain. With extracellular fluid, it reaches the regions surrounding structures responsible for trigeminohypoglossal reflex. Thus, it can be presumed that the concentrations of the peptide, effective in the specific structures, are much lower than their initial concentrations. For this reason in our experiments concentration of GAL used for i.c.v. perfusion was 


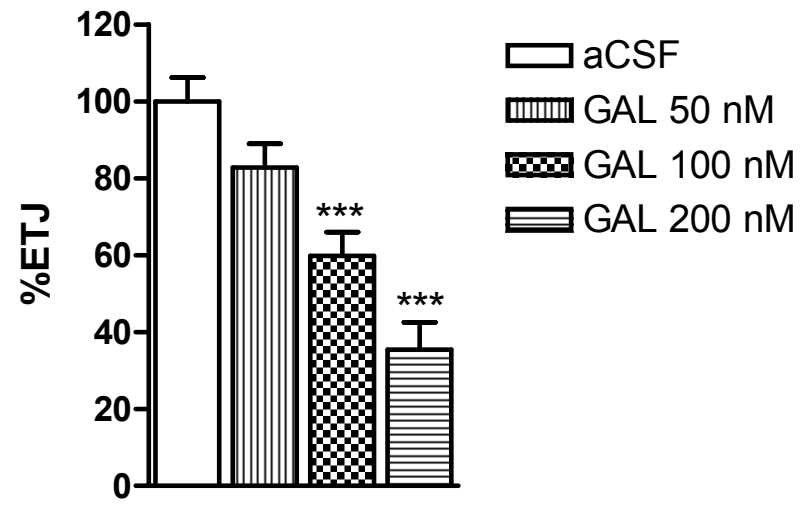

Fig. 2. Effects of perfusion of cerebral ventricles with aCSF and with 50, 100 and $200 \mathrm{nM}$ galanin (GAL) in rats on evoked tongue jerks (ETJ) induced by tooth pulp stimulation. The data represent mean \pm SEM of 10 rats per group. Amplitude of ETJ after i.c.v. perfusion with aCSF was considered a $100 \%$ response. Statistical significance used one-way ANOVA and a post-hoc multiple comparison Student Newman-Keuls test $(* * * p<0.001$ as compared to aCSF treated animals by using one-way ANOVA followed by a post-hoc multiple comparison Student NewmanKeuls test).

several times higher than in other studies where GAL was administered directly to brain nuclei (Zhang et al. 2000b, Sun et al. 2003).

Perfusion of cerebral ventricles with GAL caused a significant reduction of the amplitude of ETJ compared to control perfusion with aCSF (Fig. 1). The analgesic activity of GAL, expressed as the amplitude of the evoked retractory movement of the tongue after electrical tooth pulp stimulation (ETJ), was concentration-dependent and the values for the perfusion

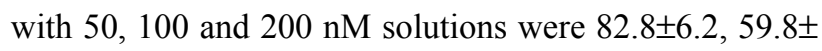
6.2 and $51.4 \pm 7.1 \%$, respectively, as compared with control regarded as a $100 \%$ (Fig. 2).

Influence of co-administration of galanin with galantide or opioid antagonists on galanin-induced analgesia in trigemino-hypoglossal reflex in rats

The effect of different antagonists on GALinduced analgesia was studied. Antagonists selected for the experiment were GAL antagonist, GLT and four opioid antagonists: non-selective Nal, $\mu$-selective $\beta$-FNA, $\delta$-selective NTI, and $\kappa$-selective nor-BNI. GAL and antagonists were all in $100 \mathrm{nM}$ concentration and GAL administration was always preceded by the perfusion with an antagonist. As expected, GLT decreased the antinociceptive effect produced by GAL. The amplitude of the ETJ increased from 56.2 \pm 5.4 to $91.2 \pm 8.1 \%$ (Fig. 3A). Similar effect was observed when cerebral ventricles were perfused with Nal or $\beta$-FNA. The
A)

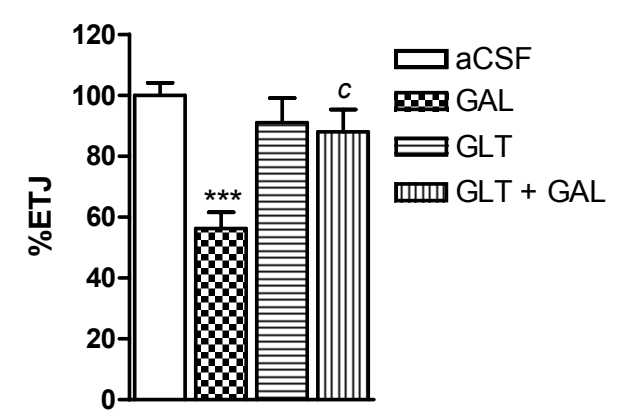

B)

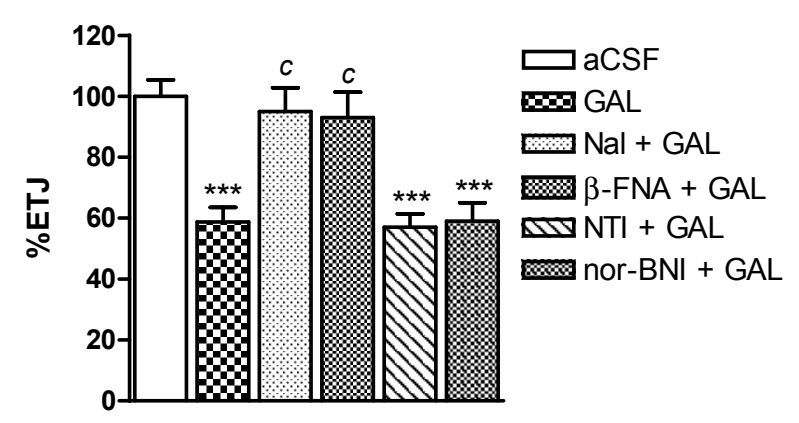

Fig. 3. Effect of antagonists: (A) galanin antagonist, galantide (GLT) and (B) opioid antagonists: non-selective naloxone (Nal), $\mu$-selective $\beta$-funaltrexamine $(\beta-F N A), \delta$-selective naltrindole (NTI), and $\mathrm{k}$-selective nor-binaltrophimine (nor-BNI), all in 100 $\mathrm{nM}$ concentration, on the amplitude of evoked tongue jerks (ETJ) induced by tooth pulp stimulation during perfusion of cerebral ventricles with $100 \mathrm{nM}$ galanin (GAL). The data represent mean \pm SEM of 10 rats per group. Amplitude of ETJ after i.c.v. perfusion with aCSF was considered a $100 \%$ response. $* * * p<0.001$ as compared to respective control by using two-way ANOVA followed by the Student Newman-Keuls' test. A two-way ANOVA analysis revealed a significant interaction between GLT and galanin: $F(1,36)=25.698,{ }^{C} p<0.001$; between naloxone and galanin: $F(1,36)=21.223,{ }^{c} p<0.001$; between $\beta$-funaltrexamine and galanin: $F(1,36)=22.368,{ }^{C} p<0.001$.

obtained ETJ values were 95.2 \pm 7.8 and 93.1 $\pm 8.4 \%$, respectively. The $\delta$ antagonist, NTI and $\kappa$ antagonist, norBNI did not suppress GAL-induced analgesia (Fig. 3B).

Influence of galantide on the endomorphin-2-induced analgesia in trigemino-hypoglossal reflex in rats

The endogenous $\mu$-opioid receptor selective ligand, EM-2, was shown to produce a strong analgesic effect in the same in vivo test (Zubrzycka et al. 2005). Here the administration of EM-2 was preceded by the perfusion of the cerebral ventricles with GAL antagonist, GLT. The amplitude of the ETJ when EM-2 was perfused alone was $30.0 \pm 4.6$ and increased to 


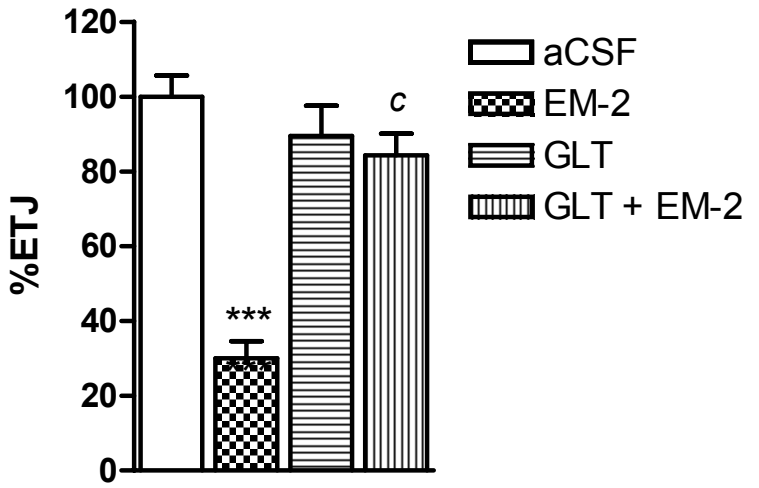

Fig. 4. Effects of perfusion of cerebral ventricles with aCSF, $\mu$ opioid agonist endomorphin-2 (EM-2, $100 \mathrm{nM})$, and galanin receptor antagonist galantide (GLT, $100 \mathrm{nM}$ ) in rats on evoked tongue jerks (ETJ) induced by tooth pulp stimulation. The data represent mean \pm SEM of 10 rats per group. Amplitude of ETJ after i.c.v. perfusion with aCSF was considered a $100 \%$ response. ${ }^{* * *} p<0.001$ as compared to respective control by using two-way ANOVA followed by the Student Newman-Keuls' test. A two-way ANOVA analysis revealed a significant interaction between galantide and endomorphin-2: $F(1,36)=24.700$, ${ }^{c} p<0.001$.

$84.3 \pm 5.8 \%$, when GLT was used (Fig. 4) which indicated that GLT strongly antagonized the antinociceptive action of the $\mu$-opioid agonist, EM-2.

Antinociceptive activity of galanin co-administered with $\mu$-opioid agonist endomorphin-2 and neurohormones oxytocin and vasopressin in trigemino-hypoglossal reflex in rats

The antinociceptive activity of GAL was significantly increased when GAL was perfused through the cerebral ventricles in combination with EM-2, OT, or AVP. The ETJ amplitude decreased from 55.8 \pm 5.7 to $21.1 \pm 2.8 \%$ for EM-2 (Fig. $5 \mathrm{~A}$ ) and to $27.3 \pm 3.2 \%$, and $35.4 \pm 2.9 \%$, when cerebral ventricles were perfused with OT and AVP, respectively (Fig. 5B, C).

\section{Discussion}

The reflexes used for over ten years in the studies of the transmission of pain within the brainstem are trigemino-digastric jaw-opening reflex (JOR) (Alentaret et al. 1997) and trigemino-hypoglossal evoked tongue jerk reflex (ETJ) (Zubrzycka et al. 1997).

In our studies we have used trigeminohypoglossal reflex to test the effects of various neuropeptides present in the cerebrospinal fluid (Zubrzycka et al. 1997, 2002). The excitation or inhibition of this reflex may be evaluated according to the mean amplitude of the recorded tongue jerks induced by
A)

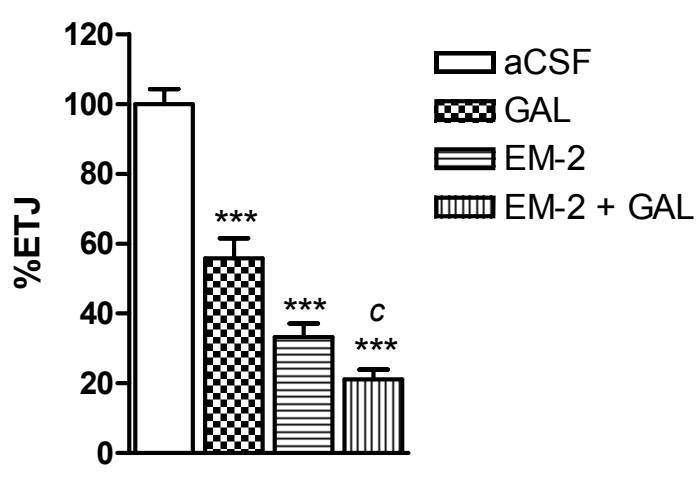

B)

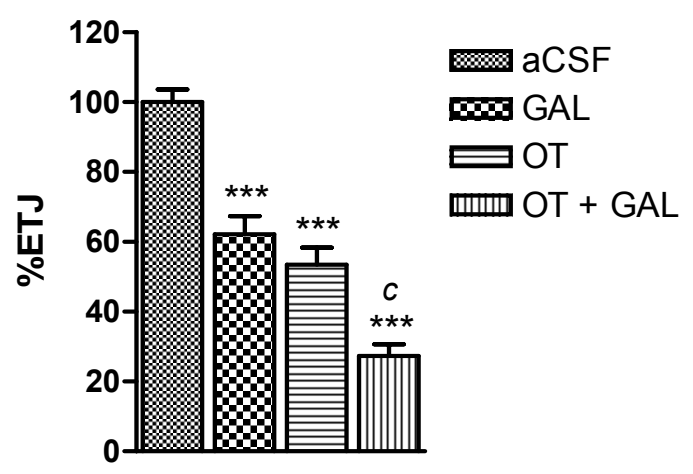

C)

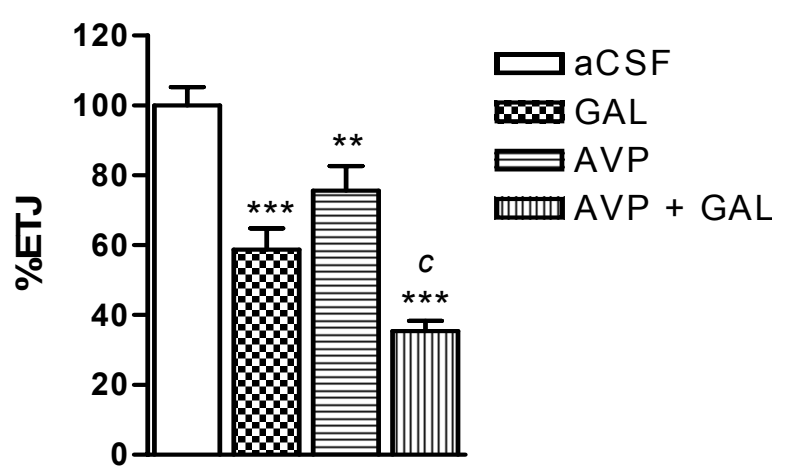

Fig. 5. Effects of perfusion of cerebral ventricles with (A) a $\mu$ opioid agonist EM-2, (B) oxytocin (OT) and (C) vasopressin (AVP) in combination with galanin (GAL) in rats on evoked tongue jerks (ETJ) induced by tooth pulp stimulation. The data represent mean \pm SEM of 10 rats per group. Amplitude of ETJ after i.c.v. perfusion with aCSF was considered a $100 \%$ response. $* * p<0.01 ; * * * p<0.001$ as compared to respective control by using two-way ANOVA followed by the Student Newman-Keuls' test. A two-way ANOVA analysis revealed a significant interaction between endomorphin-2 and galanin: $F(1,36)=23.420,{ }^{c} p<0.001$; between oxytocin and galanin: $F(1,36)=22.526, c p<0.001$; between vasopressin and galanin: $F(1,36)=26.140,{ }^{c} p<0.001$. 
incisor pulp stimulation during perfusion of the cerebral ventricles with the solution of tested compounds.

Our studies indicate that GAL exerts its antinociceptive action on the ETJ center located in the vicinity of the third and fourth cerebral ventricles, as well as on nerve $\mathrm{V}$ sensory nuclei. The afferent impulses induced by stimulation reached, via the inferior alveolar nerve fibers and the trigeminal ganglion, the nucleus sensorius principalis n.V. From the sensory nuclei, impulsation was transmitted to motoneurons located under the fundus of the fourth ventricle, concentrated in the hypoglossal motor nucleus and then via hypoglossal nerve fibers to the muscles of the tongue, causing tongue jerks.

For several years we have been studying the role of different neuropeptides (Met-enkephalin, EM-2, OT and AVP) on nociception in trigemino-hypoglossal reflex. In the present study we have demonstrated the antinociceptive effect of GAL, perfused through the cerebral ventricles alone or in combination with other neuropeptides/neurohormones, on trigemino-hypoglossal reflex in rats. GAL was shown to produce a concentration-dependent analgesic effect, which was blocked by a GAL antagonist, GLT. The antinociceptive effect of GAL was also reversed by opioid receptor antagonists, non-selective naloxone and $\mu$-selective $\beta$-FNA, but $\delta$ - and $\mathrm{K}$-selective opioid antagonists had no effect on GAL-induced antinociception. These results indicate that GAL exerts its antinociceptive effects in the orofacial area through the $\mu$-opioid receptor. Attenuation of antinociception by opioid receptor antagonists is consistent with other studies showing that analgesic effect of GAL in the spinal cord (Zhang et al. 2000a), periaqueductal central gray (PAG) (Wang et al. 1999, 2000) or arcuate nucleus (Sun and $\mathrm{Yu}$ 2005) was attenuated by naloxone. Similar findings were reported at the spinal level (Sun and Yu 2005, Zhang et al. 2000b), where the analgesic effect of GAL was attenuated by the $\mu$ - but not $\delta$ - and $\kappa$-opioid receptor antagonists. These results suggest that GAL can modulate the release of the $\mu$-selective opioids in the CNS. Furthermore, the present results showed that GLT can antagonize the antinociceptive effect of the $\mu$-opioid agonist, EM-2. Thus, GLT abolishes the inhibitory effect of both GAL and EM-2 on ETJ, which further indicates that the interactive function between the opioid and galaninergic systems is mediated by the $\mu$-opioid receptors.

Earlier we have shown that OT and AVP (Zubrzycka et al. 2005, Zubrzycka and Janecka 2005) produced a significant antinociceptive effect after i.c.v. administration, as assayed in the same experimental setting (Zubrzycka et al. 2005). Inhibition of this effect was mediated by opioid receptors, indicating that there is a synergy between oxytocin, vasopressin and opioid systems in transmitting and modulating pain stimuli. Here we showed that GAL also influences the analgesic activity in the trigemino-hypoglossal reflex arc and enhances the antinociceptive effect of EM-2, OT and AVP. These data support earlier results of others, showing that GAL potentiated the effect of morphine at the spinal level (Wiesenfeld-Hallin et al. 1990, Hua et al. 2004).

In conclusion, our results demonstrate that in the orofacial area analgesic activity exerted by opioids is modulated by GAL, OT and AVP.

\section{Conflict of Interest}

There is no conflict of interest.

\section{Acknowledgements}

The authors are grateful for the technical assistance of Mrs. Anna Kliszko. This work was supported by a grant No 503-8079-1 from Medical University of Lodz.

\section{References}

ALANTAR A, AZERAD J, LIMOGE A, ROBERT C, ROKYTA R, POLLIN B: Potentation of fentanyl suppression of jaw-opening reflex by transcranial electrical stimulation. Brain Res 763: 14-20, 1997.

BLAKEMAN KH, HAO JX, XU XJ, JAKOBY AS, SINE J, CREWLEY JN, IISMAA T, WIESENFELD-HALLIN Z: Hyperalgesia and increased neuropathic pain-like response in mice lacking galanin receptors. Neuroscience 117: 221-227, 2003.

BRANCHEK T, SMITH KE, WALKER MW: Molecular biology and pharmacology of galanin receptors. Ann NY Acad Sci 863: 94-107, 1998.

BRANCHEK T, SMITH KE, GERALD C, WALKER MW: Galanin receptors subtypes. Trends Pharmacol Sci 21: 109-117, 2000. 
DAFNY N, DONG WQ, PRIETO-GOMEZ C, REYES-VAZQUEZ C, STANFORD J, OIAO JT: Lateral hypothalamus: site involved in pain modulation. Neuroscience 70: 449-460, 1996.

DANIEL AR, LEDERIS K: Release of neurohypophysial hormones in vitro. J Physiol Lond 190: 171-187, 1967.

DE GROOT J: The Rat Forebrain in Stereotaxic Coordinates. Amsterdam, 1963.

GAI WP, GEFFEN LB, BLESSING WW: Galanin immunoreactive neurons in the human hypothalamus: coclocalization with vasopressin-containing neurons. J Comp Neurol 298: 265-289, 1990.

GUNDLACH AL: Galanin/GALP and galanin receptors: role in central control of feeding, body weight/obesity and reproduction? Eur J Pharmacol 440: 255-268, 2002.

HUA XY, HAYES CS, HOFER A, FITZSIMMONS B, KILK K, LANGEL U, BARTFAI T, YAKSH TL: Galanin acts at GalR1 receptors in spinal antinociception: synergy with morphine and AP-5. J Pharmacol Exp Ther 308: 574-582, 2004.

HUA XY, SALGADO KF, GU G, FITZSIMMONS B, KONDO I, BARTFAI T, YAKSH TL: Mechanisms of antinociception of spinal galanin: how does galanin inhibit spinal sensitization? Neuropeptides 39: 211-216, 2005.

IISMAA TP, SHINE J: Galanin and galanin receptors. Results Probl Cell Differ 26: 257-291, 1999.

JANECKA A, FICHNA J, KOSSON J, ZALEWSKA-KASZUBSKA U, KRAJEWSKA M, MIROWSKI M, ROZALSKI M: Binding of the new morphiceptin analogs to human MCF-7 breast cancer cells and their effect on growth. Regul Pept 120: 237-241, 2004.

JIMENEZ-ANDRADE JM, ZHOU S, YAMANI A, VALENCIA DE ITA S, CASTANEDA-HERNANDEZ G: Mechanism by which peripheral galanin increases acute inflammatory pain. Brain Res 1056: 113-117, 2005.

LANDRY M, HÖKFELT T: Subcellular localization of preprogalanin messenger RNA in perikarya and axons of hypothalamo-neurohypophyseal magnocellular neurons: an in situ hybridization study. Neuroscience 84: 897912, 1998.

LANDRY M, VILA-PORCILE E, HÖKFELT T, CALAS A: Differential routing of coexisting neuropeptides in vasopressin neurons. Eur J Neurosci 17: 579-589, 2003.

LIU HX, BRUMOVSKY P, SCHMIDT R, BROWN W, PAYZA K, HODZIC L, POU CH, GODBOUT C, HÖKFELT T: Receptor subtype-specific pronociceptive and analgesic actions of galanin in the spinal cord: selective actions via GalR1 and GalR2 receptors. Proc Natl Acad Sci USA 98: 9960-9964, 2001.

LIU HX, HÖKFELT T: The participation of galanin in pain processing at the spinal vel. Trends Pharmacol Sci 23: 468474, 2002.

MALKMUS S, LU X, BARTFAI T, YAKSH TL, HUA XY: Increased hyperalgesia after tissue injury and faster recovery of allodynia after nerve injury in the GalR1 knockout mice. Neuropeptides 39: 217-22, 2005.

MELNIKOVA VI, RAISON D, HARDIN-POUZET H, UGRUMOV MW, CALAS A, GRANGE-MESSENT V: Noradrenergic regulation of galanin expression in the supraoptic nucleus in the rat hypothalamus. An ex vivo study. J Neurosci Res 83: 857-863, 2006.

PILCHER WH, JOSEPH SA, MCDONALD JV: Immunocytochemical localization of pro-opiomelanocortin neurons in human brain areas subserving stimulation analgesia. J Neurosurg 68: 621-629, 1988.

RAJENDREN G: Increased galanin synapses onto activated gonadotropin-releasing hormone neuronal cell bodies in normal female mice and in functional preoptic area grafts in hypogonadal mice. $J$ Neuroendocrinol 14: 435441, 2002.

SANCHEZ A, BILINSKI M, VILLAR MJ, TRAMEZZANI JH: Coexistence of neuropeptides and their possible relation to neuritic regeneration in primary cultures of magnocellular neurons isolated from adult rat supraoptic nuclei. J Histochem 33: 121-128, 2001.

SANDKÜHLER J: The organization and function of endogenous antinociceptive systems. Prog Neurobiol 50: 49-81, 1996.

SAWCHENKO PE, SWANSON LW: Immunochistochemical identification of neurons in the paraventricular nucleus of the hypothalamus that project to the medulla or to the spinal cord in the rat. $J$ Comp Neurol 205: 260-272, 1982.

SUN YG, YU LC: Interactions of galanin and opioids in nociceptive modulation in the arcuate nucleus of hypothalamus in rats. Regul Pept 124: 37-43, 2005. 
SUN YG, GU XL, LUNDBERG T, YU LC: An antinociceptive role of galanin in the arcuate nucleus of hypothalamus in intact rats and rats with inflammation. Pain 106: 143-150, 2003.

TATEMOTO K, RÖKAEUS A, JÖRNVALL H, MCDONALD TJ, MUTT V: Galanin - a novel biologically active peptide from porcine intestine. FEBS Lett 164: 124-128, 1983.

WANG D, YE HH, YU LC, LUNDEBERG T: Intra-periaqueductal grey injection of galanin increases the nociceptive response latency in rats, an effect reversed by naloxone. Brain Res 834: 152-154, 1999.

WANG D, LUNDEBERG T, YU LC: Antinociceptive role of galanin in periaqueductal grey of rats with experimentally induced mononeuropathy. Neuroscience 96: 767-771, 2000.

WATERS SM, KRAUSE JE: Distribution of galanin-1,-2 and -3 receptor messenger RNAS in central and peripheral rat tissues. Neuroscience 95: 265-271, 2000.

WIESENFELD-HALLIN Z, XU XJ, VILLAR MJ, HÖKFELT T: Intrathecal galanin potentiates the spial analgesic effect of morphine electrophysiological and behavioral studies. Neurosci Lett 109: 217-221, 1990.

WIESENFELD-HALLIN Z, XU XJ: Neuropeptides in neuropathic and inflammatory pain with special emphasis on cholecystokinin and galanin. Eur J Pharmacol 429: 49-59, 2001.

WIESENFELD-HALLIN Z, XU XJ, CRAWLEY NJ, HÖKFELT T: Galanin and spinal nociceptive mechanisms: recent results from transgenic and knock-out models. Neuropeptides 39: 207-210, 2005.

XU XJ, WIESENFELD-HALLIN Z, VILLAR MJ, FAHRENKRUG J, HÖKFELT T: On the role of galanin, substance $\mathrm{P}$ and other neuropeptides in primary sensory neurons of the rat: studies on spinal reflex excitability and peripheral axotomy. Eur J Neurosci 2: 733-743, 1990.

XU XJ, HÖKFELT T, BARTFAI T, WIESENFELD-HALLIN Z: Galanin and spinal nociceptive mechanisms: recent advances and therapeutic implications. Neuropeptides 34: 137-147, 2000a.

XU SL, LUNDEBERG T, YU LC: Effects of galanin on wide-dynamic range neuron activity in the spinal dorsal horn of rats with sciatic nerve ligation. Regul Pept 95: 19-23, $2000 \mathrm{~b}$.

ZHANG YP, LUNDEBERG T, YU LC: Interactions of galanin and morphine in the spinal antinociception in rats with mononeuropathy. Brain Res 852: 485-487, 2000a.

ZHANG YP, YU LC, LUNDEBERG T: An interactions of opioids and galanin in dorsal horn of the spinal cord in mononeuropathic rats. Regul Pept 86: 89-94, 2000b.

ZUBRZYCKA M, JANECKA A, KOZIOŁKIEWICZ W, TRACZYK WZ: Inhibition of tongue reflex in rats by tooth pulp stimulation during cerebral ventricle perfusion with (6-11) substance P analogs. Brain Res 753: 128-132, 1997.

ZUBRZYCKA M, FICHNA J, JANECKA A: Effect of cerebral ventricles perfusion with morphiceptin and Metenkephalin on trigemino-hypoglossal reflex in rats. JPhysiolPharmacol 53: 741-750, 2002.

ZUBRZYCKA M, FICHNA J, JANECKA A: Inhibition of trigemino-hypoglossal reflex in rats by oxytocin is mediated by mu and kappa opioid receptors. Brain Res 1035: 67-72, 2005.

ZUBRZYCKA M, JANECKA A: Effec ts of centrally administered vasopressin on orofacial pain perception in rats. Brain Res 1051: 112-116, 2005. 